\title{
O IMPACTO DA COMPOSTAGEM DOMÉSTICA EM UMA COMUNIDADE NO MUNICÍPIO DE CODÓ (MA)
}

THE IMPACT OF DOMESTIC COMPOSTING IN A COMMUNITY IN THE MUNICIPALITY OF CODÓ (MA)

EL IMPACTO DEL COMPOSTAJE DOMÉSTICO EN UNA COMUNIDAD DEL MUNICIPIO DE CODÓ (MA)

\section{Jailson Pinheiro Silva de \\ Sales \\ (iD) 9 \\ Graduação em Licenciatura Interdisciplinar em Ciências Naturais/ Biologia (UFMA) jailsonsales2012@gmail.com}

\section{Wyara Cordeiro Valença Herculano

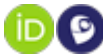

Mestre em Engenharia Agrícola (UNIVASF)

wyara.valenca@hotmail.com

\section{Camila Campêlo de Sousa (iD) 9 \\ Doutorado em Ciências (USP) \\ Professor na Universidade Federal do Maranhão (UFMA) \\ camila.campelo@ufma.br}

\begin{abstract}
Resumo
Compostagem é o processo de transformação da matéria orgânica em adubo, que possui benefícios ambientais e econômicos. Esse estudo objetivou promover a compostagem em uma comunidade do município de Codó (MA) como alternativa para a redução do lixo doméstico e a adoção de hábitos de vida mais saudáveis. Trata-se de uma pesquisa de campo com a aplicação de questionários para avaliação da percepção socioambiental de estudantes e moradores da comunidade em torno da escola, além da ministração de palestras e de oficinas para a construção de composteiras domésticas. Neste estudo, $40 \%$ dos participantes consideraram o lixo como o principal problema ambiental do município; 62,5\% desconheciam a compostagem; e 65\% dos participantes construíram uma composteira doméstica e passaram a utilizá-la. Quanto às mudanças de hábitos, 52,5\% relataram que repensaram seus hábitos de descarte, inferindo-se que a compostagem pôde estimular o desenvolvimento de hábitos de vida mais saudáveis e redução do lixo.
\end{abstract}

Palavras-chave: Composteira Doméstica. Lixo doméstico. Educação ambiental.

Recebido em: 29 de abril de 2021.

Aprovado em: 16 de novembro de 2021.

Como citar esse artigo (ABNT):

SALES, Jailson Pinheiro Silva de; HERCULANO, Wyara Cordeiro Valença; SOUSA, Camila Campêlo de. O impacto da compostagem doméstica em uma comunidade no município de Codó (MA). Revista Prática Docente, v. 6, n. 3, e089, 2021. http://doi.org/10.23926/RPD.2021.v6.n3.e089.id1148 


\section{Abstract}

Composting is the process of transforming organic matter into fertilizer, which has environmental and economic benefits. This study aimed to promote composting in a community in the municipality of Codó (MA) as an alternative for the reduction of household waste and the adoption of healthier lifestyle habits. This is a field research with the application of questionnaires to assess the socio-environmental perception of students and residents of the community around the school, in addition to giving lectures and workshops for the construction of domestic composters. In this sense, $40 \%$ of the participants consider garbage as the main environmental problem in the municipality; $62.5 \%$ were unaware of composting; and $65 \%$ of the participants built a domestic composter and started using it. As for changes in habits, $52.5 \%$ reported that they rethought their disposal habits, implying that composting could stimulate the development of healthier living habits and reduction of waste.

Keywords: Domestic Compost. Domestic waste. Environmental education.

\section{Resumen}

El compostaje es el proceso de transformación de materia orgánica en fertilizante, que tiene beneficios ambientales y económicos. Este estudio tuvo como objetivo promover el compostaje en una comunidad del municipio de Codó (MA) como alternativa para la reducción de residuos domésticos y la adopción de hábitos de vida más saludables. Se trata de una investigación de campo con la aplicación de cuestionarios para evaluar la percepción socioambiental de los estudiantes y vecinos de la comunidad alrededor de la escuela, además de impartir charlas y talleres para la construcción de compostadores domésticos. En este sentido, el 40\% de los participantes considera la basura como el principal problema ambiental del municipio; El 62,5\% desconocía el compostaje; y el 65\% de los participantes construyó un compostador doméstico y comenzó a usarlo. En cuanto a los cambios en los hábitos, el 52,5\% informó que reconsideró sus hábitos de eliminación, lo que implica que el compostaje podría estimular el desarrollo de hábitos de vida más saludables y la reducción de desechos.

Palabras clave: Compost doméstico. Desperdicio doméstico. Educación ambiental. 


\section{INTRODUÇÃ̃o}

O lixo é considerado um grande problema ambiental a nível mundial e quando se trata da geração de resíduos sólidos orgânicos, o Brasil é campeão. Nessa perspectiva, segundo a última pesquisa da Associação Brasileira de Empresas de Limpeza Pública e Resíduos Especiais (2020), os resíduos orgânicos compõem 45,3\% dos resíduos sólidos gerados no país, sendo o seu principal componente.

Os resíduos orgânicos, quando descartados em lugares impróprios, como os lixões e os aterros sanitários, causam sérios problemas para o meio ambiente e a saúde pública. Maragno e colaboradores (2007) relatam que esses resíduos são danosos ao meio ambiente quando misturados aos inorgânicos, pois produzem o chorume, um líquido tóxico resultado da sua decomposição. Porém, o chorume pode ser bastante nutritivo e se transformar em um biofertilizante natural por meio da compostagem, processo citado por Guidoni e colaboradores (2013) como uma alternativa para a solução do manejo adequado dos resíduos urbanos, cujo principal objetivo é diminuir a quantidade de lixo sólido doméstico despejado nos aterros sanitários.

A Política Nacional dos Resíduos Sólidos (lei n 12.305/2010) no art. 36, inciso V, prevê que é de responsabilidade dos municípios implantar um sistema de compostagem para resíduos sólidos orgânicos (BRASIL, 2010). O Ministério do Meio Ambiente (2005, p. 121) define compostagem como "[...] um processo no qual a matéria orgânica putrescível (restos de alimentos, aparas e podas de jardins etc.) é degradada biologicamente, obtendo-se um produto que pode ser utilizado como adubo".

A compostagem, portanto, é importante porque, além de transformar os resíduos orgânicos em composto, possui diversos outros benefícios para o meio urbano e rural, entre os quais ressalta-se: aproveitamento dos resíduos orgânicos que constituem mais da metade do lixo domiciliar; economia de aterro; aproveitamento agrícola da matéria orgânica; reciclagem de nutrientes para o solo; melhora da qualidade do solo, pois a matéria orgânica compostada se liga às partículas (areia, limo e argila) formando pequenos grânulos que ajudam na retenção e na drenagem da água e melhora a aeração; aumento do número de minhocas, insetos e microrganismos desejáveis, reduzindo a incidência de doenças de plantas; economia de tratamento de efluentes; eliminação de patógenos devido à alta temperatura atingida no processamento; e favorecimento da redução dos índices de poluição do solo, água e ar 
(MINISTÉRIO DO MEIO AMBIENTE, 2005; SARTORI, 2011; MONTEIRO, 2016; VILHENA, 2018).

De acordo com Pires e colaboradores (2014), cabe às instituições desenvolverem ações voltadas para a educação ambiental nas comunidades para a difusão de conhecimento, haja vista os problemas ambientais que as cercam cotidianamente.

A estratégia da construção da composteira domiciliar tem grande relevância, pois, além da reutilização dos resíduos orgânicos por meio da compostagem, possibilita a reflexão de questões ambientais, como a redução do lixo e, consequentemente, do consumismo e da retirada dos recursos naturais de forma desequilibrada do meio ambiente.

Logo, essa pesquisa teve como temática principal trabalhar a Educação Ambiental em uma comunidade do município de Codó (MA) por meio do incentivo à compostagem, uma vez que, segundo dados da Secretária Municipal de Meio Ambiente, Finanças e Planejamento (2018), não há coleta seletiva e o descarte dos resíduos sólidos da cidade ainda é no lixão.

O objetivo geral deste estudo foi promover a sensibilização para a prática da compostagem doméstica em uma comunidade urbana, como alternativa sustentável para a redução do lixo doméstico e a adoção de hábitos de vida mais saudáveis, por meio da Educação Ambiental.

\section{Metodologia}

\subsection{LOCAL DO ESTUDO}

Codó é um município brasileiro do estado do Maranhão localizado na mesorregião do leste maranhense. Seu território é de $4.361,344 \mathrm{~km}^{2}$ com população estimada em 2020 de 123.116 habitantes (IBGE, 2020). O índice de desenvolvimento humano (IDH) da cidade atinge o índice de 0,595 ficando na $67^{\text {a }}$ posição entre os 217 municípios do estado. O esgotamento sanitário adequado do município é de $24,2 \%$, porcentagem muito baixa, considerando que Codó é o sexto mais populoso do estado (IBGE, 2010).

A comunidade escolhida para a realização do trabalho foi a do Bairro São Francisco, uma região carente de infraestrutura, lazer e saúde e pouco desenvolvida economicamente (Figura 1). 
Figura 1 - Mapa do Maranhão com destaque para o município de Codó e em demarcação amarela as localidades da comunidade do Bairro São Francisco

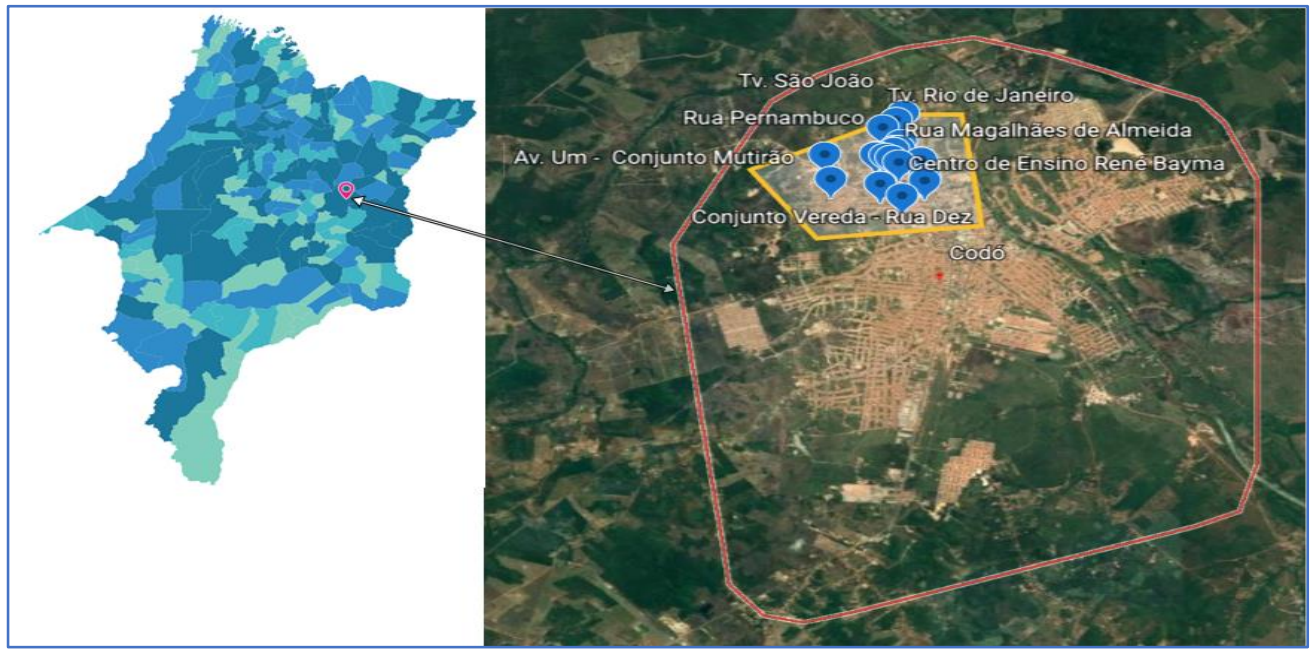

Fonte: IBGE (2020); Google Earth (2021) editado.

\subsection{MÉtOdos UTILIZADOS PARA A COLETA DE DADOS}

O presente trabalho é uma pesquisa de campo com a aplicação de questionários online e presencial e realização de entrevistas semiestruturadas. Foram realizadas uma palestra e uma oficina para a construção de um modelo de composteira doméstica, tendo em vista que a maioria dos moradores não detinham o conhecimento sobre o tema.

\subsection{AMOSTRAGEM E ANÁLISE}

Os dados coletados foram tratados em planilha no Microsoft Excel para posterior análise a partir de estatística quantitativa descritiva. A pesquisa quantitativa analisa e classifica todos os dados que podem ser quantificáveis (VIEIRA, 2010). Segundo Proetti (2017), apesar das muitas divergências que há entre as pesquisas qualitativas e quantitativas, esses dois métodos podem ser usados de forma conjunta quando se pretende compreender e verificar os fatos estudados.

A amostragem dos sujeitos comunitários foi a do tipo não probabilística e por conveniência. A base amostral contou com o envolvimento de 40 pessoas, escolhidas aleatoriamente, todas moradoras da comunidade estudada.

\subsection{CONSTRUÇÃO DE UMA COMPOSTEIRA DOMÉSTICA}

Para a construção da composteira doméstica, foram utilizadas garrafas de polietileno tereftalato (PET), um modelo de menor escala, mas de fácil acesso podendo ser encontrada facilmente pelos participantes. As garrafas foram distribuídas pelos autores para os 
participantes que despertaram o interesse em construir uma composteira. As garrafas foram recursos didáticos na proposta pedagógica para a construção de composteiras.

\subsection{APLICAÇÃO DA PESQUISA DE CAMPO}

A pesquisa foi realizada na modalidade híbrida, durante a qual os questionários foram disponibilizados na forma online para estudantes da escola estadual localizada no bairro São Francisco, Centro de Ensino René Bayma, e de forma presencial com outros moradores da comunidade.

A pesquisa contou com a participação efetiva de 18 alunos do primeiro ano do Ensino Médio. Os outros 22 participantes, residentes em torno da escola, foram escolhidos aleatoriamente, por meio de visitas às residências dos moradores, tendo sido realizado o distanciamento social e a utilização de máscaras, devido à pandemia do novo coronavírus (COVID-19). Todos os 40 participantes concordaram em participar da pesquisa e assinaram um Termo de consentimento livre e esclarecido.

Os estudos se iniciaram em setembro de 2020 com a aplicação do primeiro questionário de forma online pela plataforma Google Forms. A palestra e a oficina ocorreram pela plataforma Google Meet.

As perguntas do primeiro questionário envolviam questões de identificação de aspectos socioeconômicos (escolaridade, idade, renda, números de pessoas na residência), além de questões de aspectos ambientais, como conhecimento sobre resíduos orgânicos e inorgânicos, compostagem, reciclagem, descarte do lixo e principais problemas ambientais da comunidade.

O segundo questionário foi composto por cinco perguntas e aplicado, em outubro de 2020, sete dias após a realização da palestra e da oficina, com o intuito de verificar o grau de assimilação do conteúdo pelos participantes e o interesse deles pela construção de uma composteira doméstica em suas residências. Neste questionário, perguntou-se acerca de conceitos de composteira e o processo de compostagem, alimentos permitidos e proibidos na compostagem e indagou-se acerca da intencionalidade de construir uma composteira doméstica.

O terceiro e último questionário foi aplicado nos meses de janeiro e fevereiro de 2021, em virtude de já se ter decorrido alguns meses do processo da decomposição da matéria orgânica por meio da composteira doméstica construída em suas residências, com o intuito de analisar como esse processo influenciou nos hábitos de descarte, de consumo e alimentares dos participantes. No último questionário, foram realizadas perguntas acerca do processo de compostagem realizado, questionou-se sobre a construção da composteira, possíveis 
dificuldades, produção de chorume, importância da compostagem, destinação do lixo no domicílio, realização de reciclagem e sobre a ocorrência de mudança de hábitos após a intervenção.

Os participantes tiveram que realizar a segregação do lixo orgânico de suas casas a ser depositado na composteira feita com as garrafas pet e acompanhar o processo de dois a três meses, tempo estimado para que o composto fique pronto.

Dependendo do volume de resíduos orgânicos que geram em suas residências, cada morador utilizou de duas a três garrafas pet para construir as composteiras, seguindo os procedimentos explicados durante a oficina.

$\mathrm{Na}$ palestra, foram abordados alguns conceitos básicos da Educação Ambiental, as consequências do descarte inadequado do lixo e a importância da separação do resíduo sólido doméstico, a utilização do processo de compostagem como solução para o desperdício e a redução do lixo orgânico e como construir uma composteira doméstica com materiais reutilizáveis.

Para que fosse possível a realização da oficina nesse formato, foi elaborado um vídeo explicativo, de modo que foram apresentadas as etapas de como construir uma composteira doméstica com materiais reutilizáveis, de fácil acesso e que possivelmente iriam ser destinados ao ambiente de maneira errada. O vídeo da oficina, com 37:18 minutos de duração, foi disponibilizado pelos autores no canal do Youtube intitulado "Bio em foco"1.

O segundo momento da pesquisa teve início com visitas às casas dos moradores, etapa na qual os questionários foram aplicados de forma presencial por meio de entrevistas semiestruturadas. Ressalta-se que, durante as visitas, foi feito o uso de máscara e respeitado o distanciamento de $1,50 \mathrm{~m}$, como medidas de prevenção contra a COVID-19. Por fim, era apresentado aos moradores um modelo de composteira doméstica feita com garrafa pet (Figura 2) como alternativa sustentável para a redução do lixo orgânico doméstico, além de orientá-los como construir uma em suas casas. Entregou-se, também, um folheto explicativo com os alimentos que poderiam ir ou não para a composteira e com dicas e soluções para eventuais problemas. A pesquisa teve seu desfecho em fevereiro de 2021 com aplicação das últimas entrevistas com os moradores.

\footnotetext{
${ }^{1}$ Disponível em: https://www.youtube.com/channel/UCazeYleKCgIsOo73pw50ihA. 
Figura 2 - Imagens de algumas composteiras feitas pelos participantes da pesquisa

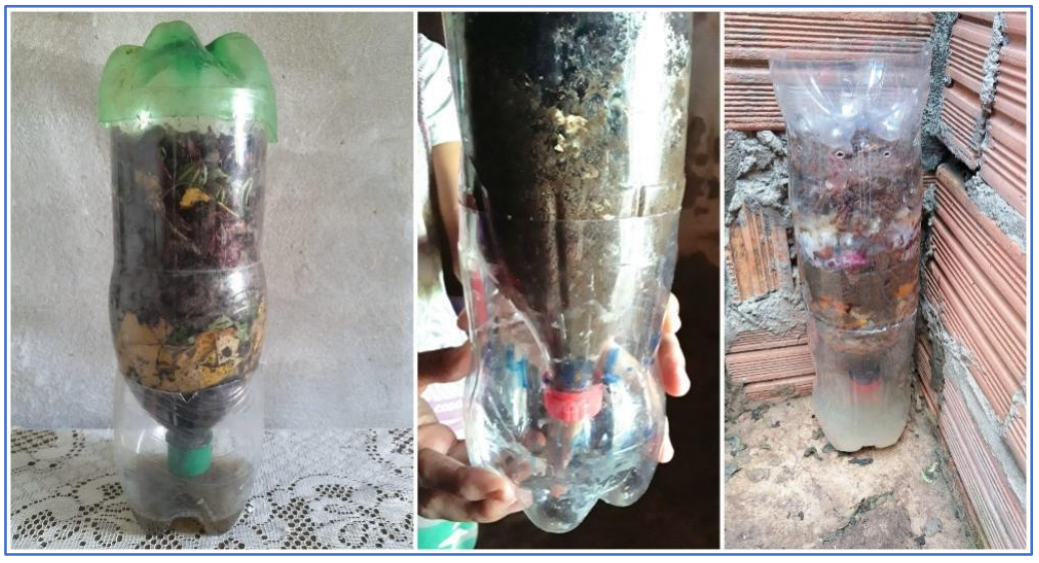

Fonte: Sujeitos comunitários (2020).

\section{Resultados E Discussões}

Este estudo contou com a participação de 40 moradores de vinte pontos diferentes da comunidade do Bairro São Francisco de Codó (MA), sendo 21 do sexo masculino e 19 do sexo feminino, dados diferentes dos estudos similares realizados por Silva e colaboradores (2018) e Carneiro (2018), que relataram predomínio de pessoas do sexo feminino.

Com relação à renda familiar, $15(37,5 \%)$ dos entrevistados afirmaram que sua renda familiar gira em torno do valor de dois salários mínimos, 14 (35\%) relataram que ganhavam um salário mínimo, 7 (17,5\%) menos de um salário mínimo e apenas 4 (10\%) tinham uma renda de três salários mínimos ou mais; de forma que 52,5\% dos entrevistados ganhavam menos de dois salários mínimos. Silva e colaboradores (2018) apontam em seu estudo que em torno de $62 \%$ da comunidade participante ganhava até dois salários mínimos.

Quanto à idade dos moradores, 40\% do público tinha de 15 a 18 anos; 57,5\%, entre 19 a 30 anos e 2,5\% tinha acima de 41 anos. Os resultados mostraram o nível de interesse maior por parte do público jovem, assim como o encontrado por Silva e colaboradores (2018), onde a maioria (63\%), tinha idades entre 25 a 29 anos e $17 \%$ entre 15 a 24 anos. Entre as justificativas para a baixa participação do público com mais de 41 anos estão a falta de tempo devido ao trabalho e às tarefas de casa e a falta de conhecimento devido ao longo tempo longe das salas de aula. Desse público, duas moradoras aceitaram participar desse estudo: uma possuía Ensino Médio completo e a outra o Ensino Fundamental incompleto.

Um pouco mais da metade dos entrevistados, $65 \%$ possuía Ensino Médio completo ou em andamento e apenas 2,5\% não chegou a completar o Ensino Médio; 2,5\% não chegaram a completar o Ensino Fundamental; 7,5\% possuía Ensino Fundamental completo ou em andamento; e 22,5\% com Ensino Superior completo. Com relação à quantidade de pessoas por 
residência nas famílias dos participantes, uma pessoa (2,5\%) afirmou que mora sozinha, nove $(22,5 \%)$ pessoas responderam que moram com seis a nove pessoas e a maioria, cerca de $75 \%$ dos entrevistados, afirmou que mora com duas a cinco pessoas.

Para identificar a problemática do lixo na comunidade foram trabalhadas as seguintes perguntas com os moradores: Na sua rua tem saneamento ou o esgoto é lançado a céu aberto?; Na sua casa é feita a separação do lixo?; Quantos sacos de lixo são produzidos por semana?; Qual o tipo de lixo é mais produzido em sua casa?; Você conhece a diferença entre lixo orgânico e inorgânico?; Na sua casa você realiza reciclagem?; Quais os principais problemas ambientais que você vê na sua cidade?

A partir dessas perguntas, foi possível analisar a percepção socioambiental acerca dos problemas ambientais da comunidade. Em virtude disso, $75 \%$ dos moradores afirmaram que não têm saneamento básico no local em que residem e apenas $25 \%$ usufruem de um sistema de esgoto.

Isso corrobora com a premissa de que o saneamento básico é um grande problema político e ambiental no Brasil até mesmo para as comunidades localizadas em Estados economicamente mais fortes. Como exemplo, a nível nacional, segundo o IBGE (2017), o serviço de esgotamento sanitário está ausente em quase 39,7\% dos municípios brasileiros.

Com relação à separação do lixo domiciliar, 57,5\% afirmaram que não o fazem, em contrapartida $35 \%$ realizam a separação do lixo em suas casas e 7,5\% tentam realizar. São resultados bem próximos dos achados por Carijó (2016), que obteve um percentual de 55\% em seu estudo e bastante diferente do que apresentou Silva (2019) em um estudo desenvolvido no município de Barcarena (PA), no qual 85\% dos entrevistados informaram que separam o lixo de suas residências.

Quanto à quantidade de sacos de lixo produzida por semana na residência de cada um dos moradores, 77,5\% deles produzem de um a cinco sacos por semana, 12,5\% de seis a dez sacos, $2,5 \%$ de 11 a 15 sacos semanalmente, $5 \%$ de 16 a 25 sacos e 2,5\% não souberam informar. Dados bem próximos foram levantados por Carneiro (2018) em uma comunidade da cidade de Capim Grosso (BA), que mostraram que em média os moradores produzem 2 sacos de lixo de 30 litros por semana.

Com respeito à diferença entre lixo orgânico e inorgânico, 23 pessoas (57,5\%) mencionaram conhecer a diferença entre os dois tipos de lixo, enquanto 13 (32,5\%) alegaram não saber distinguir os dois termos e 4 (10\%) dos entrevistados disseram saber pouco, resultado 
bem próximo dos achados por Brentano e colaboradores (2018) em estudo realizado com dez moradoras de um bairro do município de Campo Bom (RS), segundo o qual mais da metade delas sabiam a diferença entre lixo orgânico e inorgânico.

Em relação ao tipo de lixo mais produzido em suas residências, os participantes podiam assinalar mais de uma alternativa e $80 \%$ informaram pelo menos dois componentes orgânicos (restos de alimento e podas de jardim) como o lixo mais produzido pelo domicílio; 52,5\% apontaram também mais de um dos componentes inorgânicos (papel, plástico, garrafas etc.) e 2,5\% não souberem responder. Resultado bem diferente dos achados de Mucelin e Bellini (2008), segundo os quais a maior parte dos entrevistados (58\%) apontou o lixo inorgânico como o mais produzido em suas residências no município de Medianeira (PR).

Verificou-se, também, se os moradores praticavam a reciclagem em seus domicílios: $75 \%$ dos entrevistados não possuíam esse hábito, $20 \%$ afirmaram que sim e $5 \%$ dos entrevistados disseram que praticavam às vezes. Alguns dos entrevistados relataram, inclusive, que não realizam essa prática porque o município não dispõe de um serviço de coleta seletiva. Um estudo realizado por Leme (2009) na cidade de Aquidauana (MS), aponta que 69,58\% dos moradores não realizam a reciclagem do lixo em seus lares; mesmo o município disponibilizando um serviço de coleta seletiva.

Diante do exposto, faz-se fundamental que o governo municipal de Codó (MA) implante um serviço de coleta seletiva no município, bem como desenvolva políticas educacionais voltadas para as questões ambientais mais robustas dentro da comunidade que visem a sensibilização dos moradores acerca de problemáticas como a do lixo.

No que se refere à destinação final que dão às sobras alimentícias, 52,5\% descartam seus resíduos no lixo para coleta convencional, 35\% utilizam como ração animal, 7,5\% dos entrevistados afirmaram que os usam como adubo para as plantas e 5\% reaproveitam em receitas culinárias. O desperdício alimentício não foi detectado no estudo de Zaro e colaboradores (2018), no qual a maior parte dos moradores de uma comunidade do município de Caxias do Sul (RS) reaproveita as sobras alimentares em outras refeições. Os autores ainda apontam a compostagem como solução para a redução desses resíduos.

No tocante aos problemas ambientais que os participantes conseguiam identificar no município de Codó, os resultados, na forma de porcentagem, encontram-se apresentados na Figura 3, os quais foram próximos aos achados por Carijó (2016), nos quais $41 \%$ dos entrevistados consideraram que o lixo é o principal problema da comunidade da Babilônia (RJ). 
Figura 3 - Principais problemas ambientais apontados pelos moradores do Bairro São Francisco

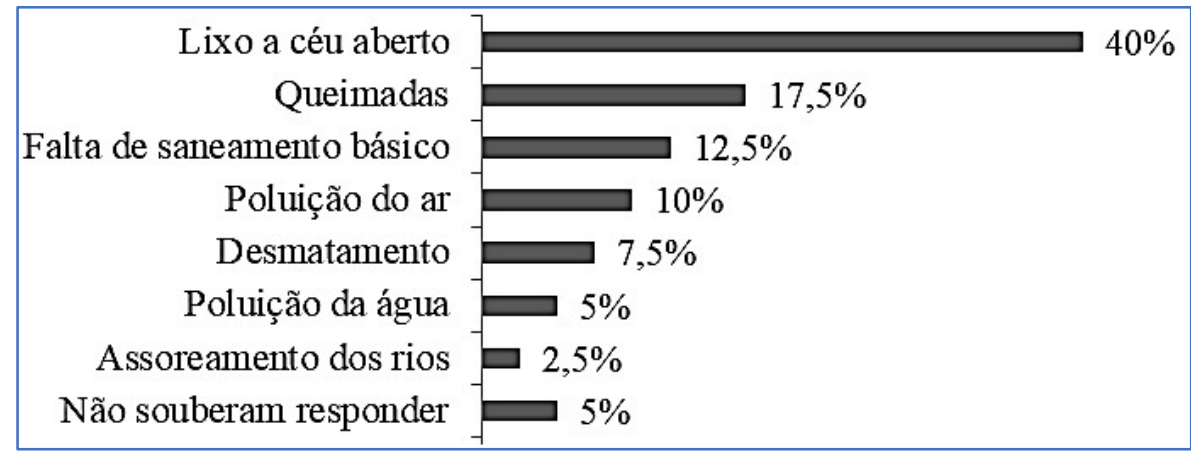

Fonte: Pesquisa (2021).

Após identificar o problema do lixo na comunidade, foi indagado aos moradores se eles conheciam a técnica da compostagem, sua importância e se a realizavam, com o intuito de compreender o nível de conhecimento dos moradores da comunidade do bairro acerca dessa temática.

Desse modo, 62,5\% dos entrevistados desconheciam a técnica da compostagem e sua importância e $27,5 \%$ afirmaram conhecer. Houve, também, os que relataram conhecer pouco sobre o assunto 7,5\% e outros 2,5\% afirmaram conhecer apenas a sua importância. Quanto ao percentual dos que disseram que praticam a técnica da compostagem, $85 \%$ afirmaram que não a fazem, outros $12,5 \%$ disseram que a executam e 2,5\% relataram que a praticam às vezes.

Esse baixo nível de conhecimento sobre a técnica da compostagem, quando comparado a outros estudos, revelou que o problema não é exclusivo do município de Codó, uma vez que Silva e colaboradores (2018) diagnosticaram que $80 \%$ dos moradores do município de Planaltina (DF) desconheciam o conceito de compostagem e Guidoni e colaboradores (2013) mostraram que de 12 pessoas de uma comunidade no município de Capão do Leão (RS), apenas cinco tinham conhecimento prévio sobre o conceito de compostagem.

Buscou-se estimar o nível de interesse dos moradores em construir uma composteira doméstica em suas residências. Para isso, perguntou-se aos entrevistados se pretendiam construir uma composteira doméstica em suas casas com materiais de baixo custo. Mais da metade dos entrevistados $(62,5 \%)$ respondeu positivamente quando questionados se pretendiam construir uma composteira em suas casas. Por outro lado, $20 \%$ responderam negativamente e 17,5\% dos entrevistados expressaram dúvida ao serem questionados. Resultado bem próximo do que apontam Silva e colaboradores (2018) e Melo e Zanta (2016) em seus estudos, com percentuais entre $75 \%$ e $78 \%$ dos moradores que declararam interesse na compostagem, respectivamente; o que pode ser considerado um resultado positivo, uma vez que a sociedade 
se demonstrou mais sensível às questões ambientais e à necessidade de consumo mais sustentável.

Alguns meses depois, os participantes foram novamente entrevistados e questionados se haviam construído uma composteira doméstica em suas residências. Caso a reposta fosse negativa, perguntou-se o motivo.

Nessa segunda entrevista, $26(65 \%)$ dos moradores chegaram a construir uma composteira doméstica em suas casas. Entre os motivos mais mencionados pelos quais os moradores que acabaram não construindo a composteira doméstica estão à falta de tempo, o esquecimento e a falta de materiais. Nesse sentido, o participante 1 argumentou: "Não, porque o material orgânico que sobra de comidas serve de alimentos para os animais (porcos) por isso não precisa de compostagem”.

Diante disso, o participante não achou necessária a prática da compostagem, por utilizar a matéria orgânica como ração animal. Um estudo realizado por Zaro e colaboradores (2018), associou a falta de interesse dos sujeitos comunitários sobre o assunto à falta de incentivos públicos e de efetivação de políticas públicas que envolvam a Educação Ambiental.

Considerando que a maioria dos moradores não sabia o que era compostagem, para aplicá-la com a comunidade fez-se necessário passar algumas orientações de como realizar esse processo em casa construindo uma composteira doméstica com materiais reutilizáveis que possivelmente parariam no lixo. Logo após o diálogo com os moradores, foram feitas as seguintes perguntas: O que é uma composteira?; Quais alimentos e resíduos são colocados na composteira?; Quais alimentos e resíduos são proibidos na composteira?

Partindo-se do que diz o Núcleo Socioambiental (2017), que define composteira como o "local ou estrutura própria para o depósito e decomposição da matéria orgânica”, foi possível analisar e interpretar como os moradores definiam composteira.

A grande maioria definiu composteira como o local onde se realiza a compostagem e outros usaram termos como recipientes e estrutura onde se realiza a compostagem, como representado na fala da participante 2: "É o nome que se dá para local ou estrutura própria para decomposição de alimentos orgânicos".

Com base nisso, foi possível dizer que 77,5\% dos moradores compreenderam de fato o que é uma composteira e 22,5\% ainda não sabiam do que se tratava, mesmo após a palestra.

Para construir uma composteira doméstica, além da escolha do local, é necessário fazer a separação da matéria orgânica que vai entrar na composteira, pois nem toda matéria orgânica 
serve para o sistema de compostagem e alguns resíduos podem atrair organismos indesejáveis proliferadores de doenças infecciosas e outros podem produzir odores desagradáveis e retardar o processo da compostagem.

Devem entrar na composteira restos de alimentos e resíduos como cascas e talos de frutas, verduras e legumes, borra e filtro de café, sachês de chá (sem etiqueta), cascas e caixa para ovos, folhas secas, galhos de poda, cascas de madeira (material de estrutura), entres outros. Já os que são proibidos na composteira são restos de carne em geral, temperos fortes, líquidos (caldos, sucos, refrigerantes, etc.), a maioria dos tipos de papel, material de higiene pessoal, fezes de animais domésticos, laticínios, derivados do trigo, ervas daninhas e plantas doentes e serragem tratada (GROSSI; VALENTE, 2002).

Com base nisso, foi perguntado aos moradores quais alimentos ou resíduos que podiam ser colocados na composteira, podendo ser assinalado mais de uma alternativa. A grande maioria, $72,5 \%$, citou restos de cascas e talos de frutas, verduras e legumes. Logo atrás vieram as cascas de ovos e caixa para ovos com $37,5 \%$, e a borra de café e filtro de café com $27,5 \%$. Outro dado a se considerar é que 7,5\% dos entrevistados citaram que os alimentos orgânicos entram na composteira, porém, como visto, nem todos os alimentos orgânicos entram na composteira.

Diante do exposto, foi possível dizer que $85 \%$ dos entrevistados citaram corretamente alimentos que entram na composteira, contudo 7,5\% ainda não compreendiam quais alimentos deveriam ser colocados na composteira e outros 7,5\% não souberam citar ou simplesmente não responderam.

Com relação aos alimentos e aos resíduos que são proibidos na composteira, os participantes também podiam assinalar mais de uma opção e $65 \%$ mencionaram os restos de carne em geral, outros $50 \%$ mencionaram as frutas cítricas e, subsequentemente, 47,5\% apontaram temperos fortes, como alho, cebola e pimenta. Porém, as frutas cítricas podem ir à composteira de forma moderada. Logo, $50 \%$ dos entrevistados citaram pelo menos um alimento que é proibido na composteira de forma equivocada. Em contrapartida, 42,5\% foram precisos ao mencionarem quais alimentos não iriam à composteira e $7,5 \%$ dos entrevistados não mencionaram ou não souberam responder.

Quando os sujeitos comunitários separam o lixo doméstico em suas residências, estão beneficiando o meio ambiente e a sociedade, visto que, de acordo com Ministério do Meio Ambiente (2005) e Vilhena (2018), essa prática facilita o trabalho dos recicladores, diminui a 
perda de matéria-prima com potencial à reciclagem, diminui o impacto ambiental e contribui com a diminuição dos gastos de serviços públicos relacionados à coleta de lixo.

Deste modo, a separação do lixo orgânico e a compostagem revelam-se como práticas sustentáveis, pois contemplam os três pilares da sustentabilidade, promovendo o desenvolvimento econômico, social e ambiental de forma segura, sem afetar os recursos naturais.

Os participantes não só obtiveram conhecimento teórico, mas aprenderam na prática como ocorre o processo da compostagem e como utilizar os produtos originados desse processo por intermédio da composteira doméstica, além de separar o lixo.

Depois de os moradores terem acompanhado o processo da compostagem, foram feitas as seguintes perguntas: Você teve dificuldade em separar o lixo para colocar na composteira?; Houve produção de chorume?; Para que serve o chorume?; Onde será colocado o chorume da sua composteira?; Pra você qual a importância da compostagem?

Quando questionados se tiveram dificuldades em separar o lixo para colocar na composteira, $75 \%$ responderam que não tiveram nenhuma dificuldade, enquanto $12,5 \%$ responderam que tiveram e outros $12,5 \%$ relataram que tiveram um pouco de dificuldade. Porém, em um estudo realizado no município de São Domingos (BA) por Melo e Zanta (2016), os moradores relataram que tiveram dificuldades apenas na disposição dos resíduos na composteira, mas quanto à segregação, não tiveram dificuldades, pois já tinham esse costume.

No que se refere ao aparecimento de insetos na composteira, 69\% dos entrevistados relataram a presença desses organismos na composteira. No estudo de Melo e Zanta (2016), os autores relatam a presença de moscas e mosquitos durante o processo em um período de 15 dias.

A presença de organismos, como moscas, mosquitos e baratas, durante o processo da compostagem, torna-se um problema por serem vetores de doenças infecciosas e geradores de odores desagradáveis, prejudicando a qualidade final do composto. Todavia, durante a prática, seguindo os estudos de Grossi e Valente (2002), Zaro e colaboradores (2018) e Núcleo Socioambiental (2017), foram repassados alguns cuidados que deveriam ter para que o composto não atraísse organismos patógenos.

No entanto, nem todo organismo é indesejável. Nessa perspectiva, Oliveira e colaboradores (2005) apontam que, além de microrganismos, como bactérias e fungos, diversos macroorganismos podem surgir para ajudar no processo da decomposição, como minhocas, 
lacraias, formigas, centopeias, besouros, aranhas e outros e seus dejetos servem de alimentos para outros organismos.

Com relação à produção de chorume, um dos produtos do processo da compostagem, 92,5\% dos participantes que fizeram uma composteira, observaram a produção de chorume. Dados bem próximos dos obtidos por Melo e Zanta (2016), os quais apontam uma produção de chorume em todas as 12 composteiras do seu estudo.

De acordo com Vital e colaboradores (2018) e Núcleo Socioambiental (2017), o chorume melhora a qualidade do solo e oferece nutrientes, proteção e resistência para as plantas contra ataques de pragas, insetos e doenças e pode ser usado diretamente no solo e borrifado nas folhas de 7 a 10 dias.

Por conseguinte, foi questionado onde os participantes colocariam o chorume produzido na composteira. Assim, 80\% responderam que colocariam nas plantas. De outro modo, 7,5\% falaram que borrifariam nas plantas e apenas $12,5 \%$ não responderam ou não sabem como utilizar.

Com relação à importância da compostagem, 15 \% dos entrevistados afirmaram que a compostagem é importante para a redução do lixo; 2,5\% para produção de alimentos; 2,5\% para coleta seletiva; 7,5\% para agricultura; $12,5 \%$ para adubação; $15 \%$ para conservação ambiental e 2,5\% para reciclagem. Em um estudo similar, realizado por Hempe (2020) em Seberi (RS), além das questões que envolvem diretamente o meio ambiente, destacaram-se também a melhoria das condições de trabalho dos funcionários do aterro, a redução dos custos para prefeitura e a melhora nas políticas voltadas para a educação ambiental do município.

$\mathrm{Na}$ última entrevista foram repetidas algumas das perguntas do primeiro questionário com o intuito de analisar a evolução dos participantes ao longo desse estudo e responder a seguinte pergunta "É possível estimular a comunidade a desenvolver hábitos de vida mais saudáveis por meio da prática da separação do lixo orgânico e da compostagem doméstica?".

Sendo assim, questionou-se novamente aos entrevistados que destino davam às sobras alimentares em suas residências e 52,5\% responderam que colocam em suas composteiras, $27,5 \%$ relataram que ainda descartavam no lixo, outros $35 \%$ colocavam para os animais e um percentual de $5 \%$ disse que reaproveita as sobras em receitas culinárias. Ressalta-se que alguns participantes assinalaram mais de uma alternativa.

Ficou evidenciada uma mudança no comportamento dos moradores quanto à destinação final que dão aos resíduos alimentares, visto que 52,5\% dos entrevistados responderam no 
princípio desse estudo que descartavam esses resíduos no lixo convencional e, ao final desse estudo, 27\% apenas tornaram a responder o questionamento afirmando que continuam descartando esses resíduos no lixo.

Considerando os benefícios que a compostagem pode trazer, questionou-se se os participantes tinham notado alguma mudança nos hábitos de consumo, de descarte, alimentares ou em algum outro aspecto. A grande maioria (78\%) respondeu que "Sim", houve alguma mudança ou foram repensados os seus hábitos, como relata um participante: "Olha repensar sim sem dúvida, e na relação do descarte de alimento logo quando eu comecei a fazer a composteira, a gente começa a repensar que esses restos de alimento eles servem pra alguma coisa e podem ser reutilizados".

Dos participantes, 52,5\% relataram que repensaram seus hábitos de descarte, enquanto $12,5 \%$ afirmaram que, com a prática da compostagem, passaram a refletir mais sobre os problemas ambientais, outros 7,5\% repensaram em seus hábitos de consumo e apenas 2,5\% disseram que sentiram alguma mudança em seus hábitos alimentares. Por outro lado, $25 \%$ dos entrevistados relataram que não perceberam nenhuma mudança quanto aos hábitos que tinham antes da prática da compostagem.

Portanto, diante dos resultados, foi possível afirmar que a prática da separação do lixo orgânico e da compostagem pode levar os sujeitos comunitários a desenvolverem hábitos de vida mais saudáveis, além de levar à reflexão sobre os problemas ambientais da comunidade. Para Guidoni e colaboradores (2013) isso acontece porque, ao acompanharem todos os processos da compostagem, os moradores são sensibilizados a desenvolverem práticas mais sustentáveis e podem disseminar esse conhecimento naturalmente para os demais sujeitos comunitários.

\section{CONSIDERAÇõES FinAIS}

O lixo foi identificado por boa parte dos moradores da comunidade como o principal problema ambiental do município, tendo como componente majoritário os resíduos orgânicos produzidos domesticamente, sendo assim, a compostagem tornou-se uma interessante alternativa para dirimir essa problemática. Nesse sentido, a construção de uma composteira doméstica viabilizou a redução do lixo dentro da comunidade, pois a maioria dos participantes passou a utilizar os restos de resíduos orgânicos produzidos em suas residências nas composteiras confeccionadas. A prática da separação do lixo orgânico e da compostagem levou 
os sujeitos comunitários a desenvolverem hábitos de vida mais saudáveis, além de fomentar a reflexão acerca dos problemas ambientais da comunidade.

\section{REFERÊNCIAS}

ASSOCIAÇÃO BRASILEIRA DE EMPRESAS DE LIMPEZA PÚBLICA E RESÍDUOS ESPECIAIS. Panorama dos resíduos sólidos no Brasil. São Paulo: ABRELPE, 2020.

BRASIL. Planalto. Lei $\mathbf{n}^{\circ} \mathbf{1 2 . 3 0 5}$ de 02 de agosto de 2010, 2010. Disponível em: http://www.planalto.gov.br/ccivil 03/ ato2007-2010/2010/lei/112305.htm. Acesso em: 03 dez. 2019.

BRENTANO, Claucia; POWDEWILS, Tamires Lopes; PEDRUZZI, Alana das Neves. Promovendo a Educação Ambiental através da compostagem domiciliar. RELACult Revista Latino-Americana de Estudos em Cultura e Sociedade, v. 04, n.1028, p. 1-10, 2018. https://doi.org/10.23899/relacult.v4i0.1028.

CARIJÓ, Renata de Sousa. Análise e proposta de uma gestão integrada de resíduos sólidos: o estudo de caso da Comunidade da Babilônia. 2016. 144 f. Rio de Janeiro: Dissertação (Mestrado em Planejamento Energético) - Universidade Federal do Rio de Janeiro, Rio de Janeiro, 2016. Disponível em:

http://www.ppe.ufrj.br/images/Renata_de_Sousa_Carij\%C3\%B3.pdf. Acesso em: 30 mar. 2021.

CARNEIRO, Renata da Silva. Gestão de resíduos sólidos na zona rural: A Percepção dos Moradores do Povoado de Caiçara, Capim Grosso/BA. 2018. 49 f. Medianeira: Tese (PósGraduação em Gestão Ambiental) - Universidade Tecnológica Federal do Paraná, Medianeira, 2018. Disponível em: http://repositorio.utfpr.edu.br/jspui/handle/1/22853. Acesso em: 20 fev. 2021.

GUIDONI, Lucas Lourenço Castiglioni; BITTENCOURT, Gustavo; MARQUES, Roger Vasques; CORRÊA, Luciana Bilhalva; CORRÊA, Érico Kunde. Compostagem Domiciliar: Implantação e Avaliação do Processo. Revista Tecnológica, v. 17, n. 1, p. 44-51, 2013. http://dx.doi.org/10.17058/tecnolog.v17i1.3640.

GROSSI, Maria Gricia; VALENTE, José Pedro Serra. Compostagem Doméstica de Lixo. São Paulo: Fundacentro, 2002.

HEMPE, Tais Cristina. Benefícios do uso da compostagem doméstica como destinação ambientalmente adequada dos resíduos orgânicos na área urbana de Seberi -RS. 2020. 58 f. Santa Maria: Trabalho de Conclusão de curso (Graduação em Engenharia Ambiental e Sanitária) - Universidade Federal de Santa Maria, Frederico Westphalen, 2020. Disponível em: https://repositorio.ufsm.br/handle/1/20228. Acesso em: 1 abr. 2021.

IBGE. Instituto Brasileiro de Geografia e Estatística. Censo demográfico e Populacional. 2020. Município de Codó - MA, 2020. Disponível em:

https://cidades.ibge.gov.br/brasil/ma/codo/panorama. Acesso em: 20 jan. 2021. 
IBGE. Instituto Brasileiro de Geografia e Estatística. Cidades 2010, 2010. Disponível em: https://cidades.ibge.gov.br/brasil/ma/codo/panorama. Acesso em: 20 jan. 2021.

IBGE. Instituto Brasileiro de Geografia e Estatística. Pesquisa Nacional de Saneamento Básico, 2017. Disponível em:

https://agenciadenoticias.ibge.gov.br/media/com mediaibge/arquivos/45f7422705c07ef3409d 076fd95bd516.pdf. Acesso em: 25 mar. 2021.

LEME, Simone Maria. Comportamento da população urbana no manejo dos resíduos sólidos domiciliares em Aquidauana - MS. Geografia, v. 18, n. 1, p. 157-192, 2009.

http://dx.doi.org/10.5433/2447-1747.2009v18n1p154

MARAGNO, Eliane Spricigo; TROMBIN, Daiane Fabris; VIANA, Ednilson. Uso da serragem no processo de minicompostagem. Engenharia Sanitária e Ambiental, Rio de Janeiro, v. 12, n. 4, p. 355-360, 2007. https://doi.org/10.1590/S1413-41522007000400001.

MELO, Simara Lobo; ZANTA, Viviana Maria. Análise do uso de compostagem doméstica em conjuntos habitacionais de interesse social na cidade de São Domingos - Bahia. Revista Eletrônica de Gestão e Tecnologias Ambientais (GESTA), v. 4, n.2, p.169-180, 2016. http://dx.doi.org/10.9771/gesta.v4i2.14395

MONTEIRO, José André Verneck. Benefícios da compostagem doméstica de resíduos orgânicos. Educação ambiental em ação, Novo Hamburgo, v. 15, n.56, p. 1-7, 2016. Disponível em: http://revistaea.org/artigo.php?idartigo=2310. Acesso em: 02 dez. 2019.

MUCELIN, Carlos Alberto; BELLINI, Marta. Lixo e impactos ambientais perceptíveis no ecossistema urbano. Sociedade e Natureza, Uberlândia, v. 20, n. 1, p. 111- 124, 2008.

MINISTÉRIO DO MEIO AMBIENTE. Lixo um grave problema no mundo moderno. Brasil: 2005.

NÚCLEO SOCIOAMBIENTAL DO TRIBUNAL SUPERIOR DO TRABALHO. Guia prático de compostagem do TST. Brasília: NSA, 2017.

OLIVEIRA, Arlene Maria Gomes; AQUINO, Adriana Maria; CASTRO NETO, Manoel Teixeira de Castro Neto. Compostagem Caseira de Lixo Orgânico Doméstico. Circular Técnica Embrapa, n. 76, p.1-6, 2005. Disponível em: https://www.embrapa.br/busca-depublicacoes/-/publicacao/1022380/compostagem-caseira-de-lixo-organico-domestico . Acesso em: 11 jul. 2020.

PIRES, Bianca Salles; OLIVEIRA, Carlos Leandro; BARBOSA, Geyse Leopoldo; CARVALHOSA, Glauber Soares; BARATA, Jade Prata Bueno; VARGENS, Marta Moniz Freire; REIS, Monica Villela; SILVEIRA, Raquel Pinhão. Educação ambiental: Conceitos e práticas na gestão ambiental pública. Rio de Janeiro: INEA, 2014.

PROETTI, Sidney. As pesquisas qualitativa e quantitativa como métodos de investigação científica: um estudo comparativo e objetivo. Revista Lumen, v. 2, n. 4, p. 1-23, 2017. http://dx.doi.org/10.32459/revistalumen.v2i4.60. 
SARTORI, Valdirene Camatti; DA SILVA-RIBEIRO, Rute; SCUR, Luciana; Pansera, Maria Regina; RUPP, Luís Carlos Diel; VENTURIN, Leandro; PANAZZOLO, Maurício Rigo; TEDESCO, Maiara; FONTANA, Vanessa; SCOPEL, Silvana; DELAZERI, Morgana; FRISKE, Jaqueline; GIRELLI, Cristiane Priscila; SOSO, Letícia; IZOLAN, Lucas; MAGRINI, Flaviane Eva; ILTCHENCO, Janaina; ANGONESE, Marcia Toigo; GAIO, Juliano. Cartilha para agricultores: adubação verde e compostagem estratégias de manejo do solo para conservação das águas. Caxias do Sul: UCS, 2011. Disponível em: https://www.ucs.br/site/midia/arquivos/Aduba\%C3\%A7\%C3\%A3o_e_Compostagem_2.pdf. Acesso em: 15 ago. 2019.

SECRETÁRIA MUNICIPAL DE MEIO AMBIENTE, FINANÇAS E PLANEJAMENTO. Prefeitura de Codó. Dados referente a gestão dos resíduos do município de Codó-MA, 2018. Disponível em: www.codo.ma.gov.br/portal/wp-content/uploads/2020/12/Dadosreferente-a-gestão-dos-resíduos do-município-de-Codó.pdf. Acesso em: 2 dez. 2020.

SILVA, Gilson de Brito; LUI, Gabriel Henrique; RIBEIRO, Elaine Nolasco; CRUZ, Tânia Cristina da Silva; SALEMI, Luís Felippe. Conhecimento de resíduos orgânicos e compostagem por uma comunidade de baixa renda de Planaltina (Distrito Federal): implicações para a compostagem em escala residencial. Ciência, tecnologia e ambiente, v. 7, n.1, p. 36 - 42, 2018. http://dx.doi.org/10.4322/2359-6643.07105

SILVA, Leticia de Freitas. Gestão de resíduos: estudo de caso com compostagem caseira na comunidade da pastoral do menor, Barcarena-PA. 2019. Dissertação (Graduação em Agronomia) - Universidade Federal Rural da Amazônia, Belém, 2019. Disponível em: https://www.bdta.ufra.edu.br/jspui//handle/123456789/1030. Acesso em: 27 mar. 2020.

STUCHI, Júlia Franco. Biofertilizante um adubo líquido de qualidade que você pode fazer. Brasília: Embrapa, 2015.

VIEIRA, José Guilherme Silva. Metodologia de pesquisa científica na prática. Curitiba: Fael, 2010.

VILHENA, André. Lixo Municipal: manual de gerenciamento integrado. $4^{\mathrm{a}}$ ed. São Paulo: IPT/CEMPRE, 2018.

VITAL, Adriana de Fátima Meira; BARBOSA, Ivson de Sousa; SANTOS, Álberi Medeiros; ANJOS, Paloma Moreira; RAMOS, Igor Campos. Compostagem de resíduos sólidos orgânicos e produção de biofertilizante enriquecido. Revista Saúde e Ciência, v. 7, n. 2, p. 339-351, 2018. https://doi.org/10.35572/rsc.v7i2.121

ZARO, Marcelo; KALSING, Rejane Margarete Schaefer; THEODORO, Heloísa. Consumo e descarte de resíduos alimentares em um bairro do município de Caxias do Sul/RS. Revista de Educação, Ciência e Tecnologia, v. 7, n. 1, p. 1-22, 2018.

https://doi.org/10.35819/tear.v7.n1.a2586

\section{Agradecimentos}

Agradecemos ao Centro de Ensino Renê Bayma e aos moradores do bairro São Francisco que aceitaram participar deste estudo. 